\title{
Heat waves in Hungarian plant production
}

\author{
Révész, A., Szenteleki, K. \& Horváth, L. \\ Corvinus University of Budapest, Faculty of Horticultural Sciences, Department of Mathematics and \\ Informatics, 1118 Budapest, Villányi út 29-43., Hungary
}

\begin{abstract}
Summary: A momentous inference of heat waves is the economic effect. The main demage after the human problems will caused by theese extreme events in agriculture. For example a long hot peiod without any percipitation can exterminate not only the annual yield, but also it can demage or in extreme situation it can destroy the whole orchard. Especially endangered most of the fruits, because an extreme summer with high temperature which usually goes hand in hand with an arid period can modify growth of the plant. Our investigations show that according to the most widely accepted climate change scenarios heat waves are expected to be essentially longer and hotter than in the past. It might happen that events we now define as heat waves last through entire summer. Although it will not be general, the length and intensity of present heat waves could also multiply. Based on data provided by some global circulation models, we might be face an event that exceeds the hottest heat waves of the $20^{\text {th }}$ century by as much as $12{ }^{\circ} \mathrm{C}$. This study also offers a survey of the methodology of heat wave definition. Besides traditional calculations, we present two unconventional methods by introducing minimum and maximum temperature heat waves. We show in what points this approach is different from those usually adopted and what extra information it may offer. As an extension of the usual studies, with considering the length of events, we analyse the development of two variants - temperature and duration - and, as a result, classify the extreme heat events according to both length and intensity.
\end{abstract}

Key words: heat waves, plant production, circulation model

\section{Data and methods}

\section{Database}

Meteorological data are coming from several sources and are to be applied for quite different kinds of purposes. Hungarian Academy of Sciences' Adaptation to Climate Change Research Group recognized the need of a WindowsXP-based viticultural data management system (FRUITMET) which can effectively help climate change impact and risk approaches with a surface of data collection, organization, management and search.

Meteorological data contains of daily minimum, maximum, mean temperature, precipitation and radiation records (CRU control database due to Mitchell, 2004 with reference time series 1901-2000 and resolution of $\left.0,5^{\circ}\right)$. The plant database contains production data from 1964. Moreover, FRUIT-MET is completed with downscaled GCM scenarios as well (GFDL, SRES, ECHAM, and PRUDENCE/A1, A2, B1, B2). The daily/monthly RegCM scenarios are of $10 \mathrm{~km}$ or $5 \mathrm{~km}$ resolution. Results are collected in Access database format for a flexible form of later applications.

\section{Basic Indicator Module}

The climatic needs of plants are fairly well documented in the literature. Climate Profile Indicator Module supports the search and analysis of some weather indicators for plants e.g.: Winkler Index $\left({ }^{\circ} \mathrm{C}\right)$, Huglin Index $\left({ }^{\circ} \mathrm{C}\right)$, Biologically Effective Day Degrees $\left({ }^{\circ} \mathrm{C}\right)$, Mean Temperature of the Warmest Month $\left({ }^{\circ} \mathrm{C}\right)$, Growing Season Maximum Temperature Average $\left({ }^{\circ} \mathrm{C}\right)$, Continentality, Spring Frost Index, Annual Rainfall (mm), Summer Rainfall (mm), Monthly Degree Days $\left({ }^{\circ} \mathrm{C}\right)$, Heat Degree Days $\left({ }^{\circ} \mathrm{C}\right)$, Harvest Maximum Temperature $\left({ }^{\circ} \mathrm{C}\right)$, Number of Rain Days in the Growing Season, Ripening Month Rainfall (mm), etc.. It is capable of implementing the actual daily meteorological data as well as RegCM scenarios.

\section{Climate Profile Indicator Module}

Applying the so-called Climate Profile Indicator Module Plus we can also create new indicators by defining lower and upper boundary conditions regarding to daily as well as monthly data. It is also possible to combine temperature (minimum, average, maximum), radiation as well as precipitation data of any time period. In the case of daily data, the system of conditions can be set up by day, while for making parameters for longer time periods (weeks, for example), linear interpolation can be applied in a very simple and user friendly way. The module makes it possible e.g. to define conditions for production quantity or quality demands or help to assess the risk of changes in occurrence and spread of pests or diseases. The software can survey and evaluate historical data and RegCM scenarios to monitor temperature, precipitation and radiation characteristics and helps to decide whether the examined variables (of the examined time series) 


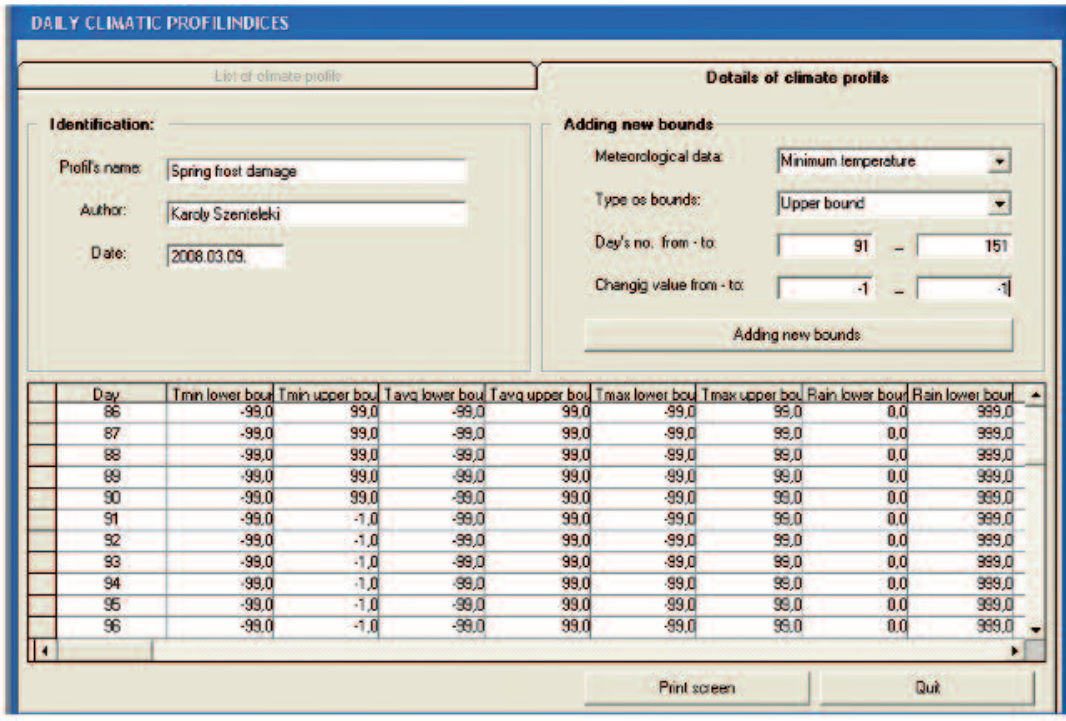

Figure 1: Defining daily profile indicators

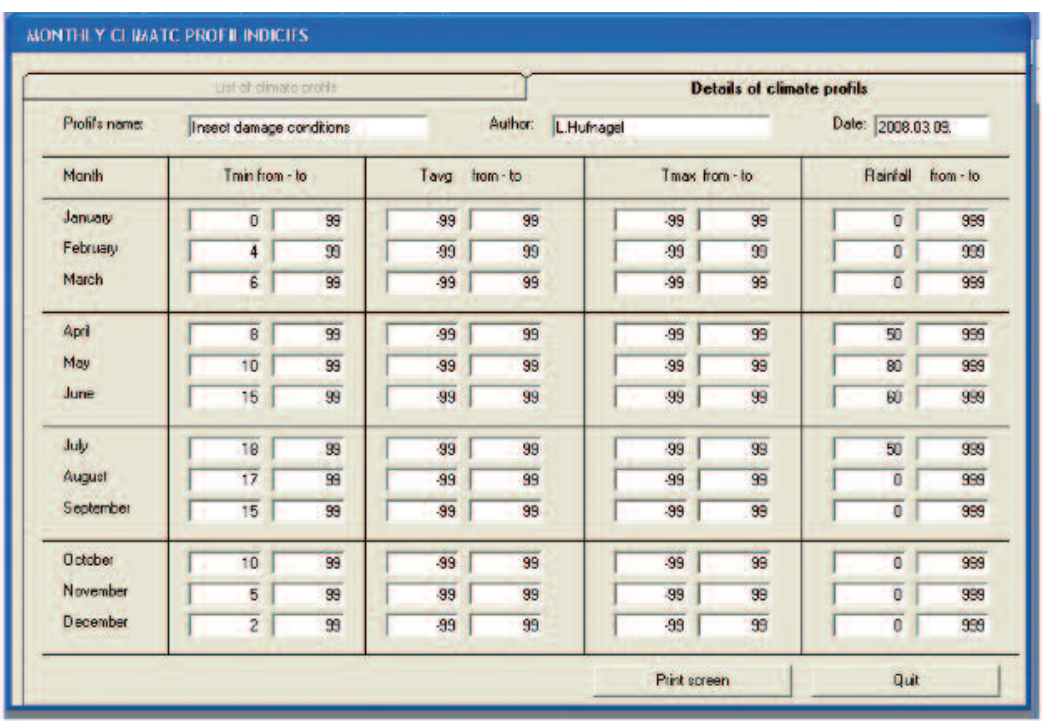

Figure 2: Defining a monthly profile

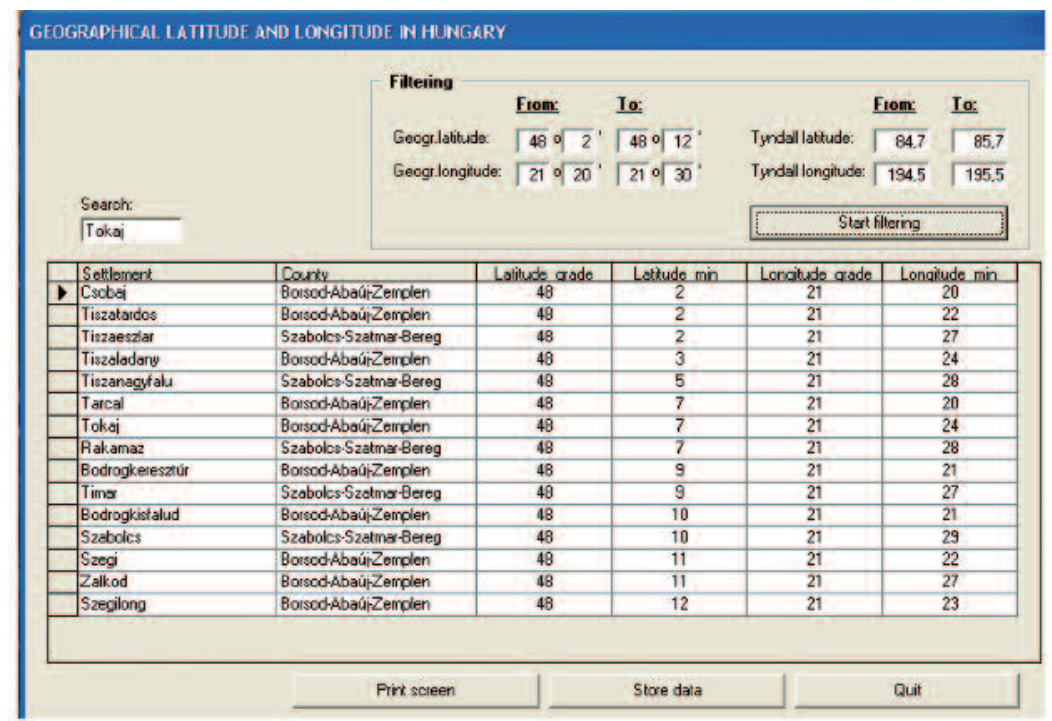

Figure 3: Tyndall coordinate transformer module indicate sufficient or not sufficient conditions, according to the profile indicators. FRUITMET is suitable also for finding the coexistence or absence of more than one meteorological profile indicators at the same time.

Figures 1 and 2 show how the daily or monthly profile indicators can be established. Each day/month, the data for the four climatic parameters must be put in separately. If no limits are desired, one need not change the initial data.

\section{Tyndall coordinate transformer}

When a certain vineyard region with longitude and latitude data are given, the transformer module can give you the Tyndall coordinates of the nearest grid point. Of course, a given the Tyndall coordinates of a meteorological station or of a vineyard, longitude and latitude can be gained easily.

\section{Statistical analysis}

After get the filtered data according to a special profile indicator or any other purpose in this module. When an extended descriptive statistical analysis to summarize and evaluate the results can make (Figure 4).

\section{Growing Season Maximum Temperature Average $\left({ }^{\circ} \mathrm{C}\right)$}

The Growing Season Maximum Temperature Average $\left({ }^{\circ} \mathrm{C}\right)$ index (Jones et al., 2005) is created from the average monthly maximum temperature of the pre-harvest months (June-September). The index is particularly important from the standpoint of sugar content, and thus grapevine quality (Figure 5).

\section{Results}

\section{The Frequency of Heat waves}

Let us compare the distribution of the length of the heat waves by this definition in Budapest and Debrecen in the periods 19012000 and 1970-2000. We need these two different time intervals to be able to decide which one to use as a base period for comparison in our subsequent enquiry.

Figure 6 shows that while the average annual frequency of heat waves increased in Budapest in the past 30 years compared to the 


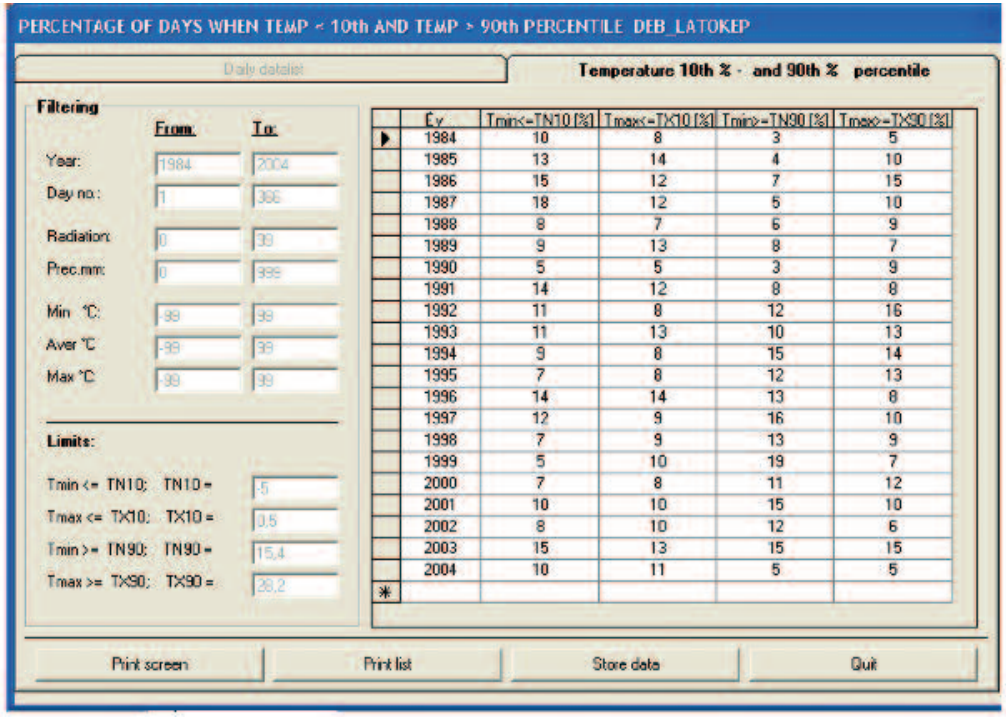

Figure 4: Frequency of days when minimum and maximum temperature is outside of the $10 \%$ and $90 \%$ quantile

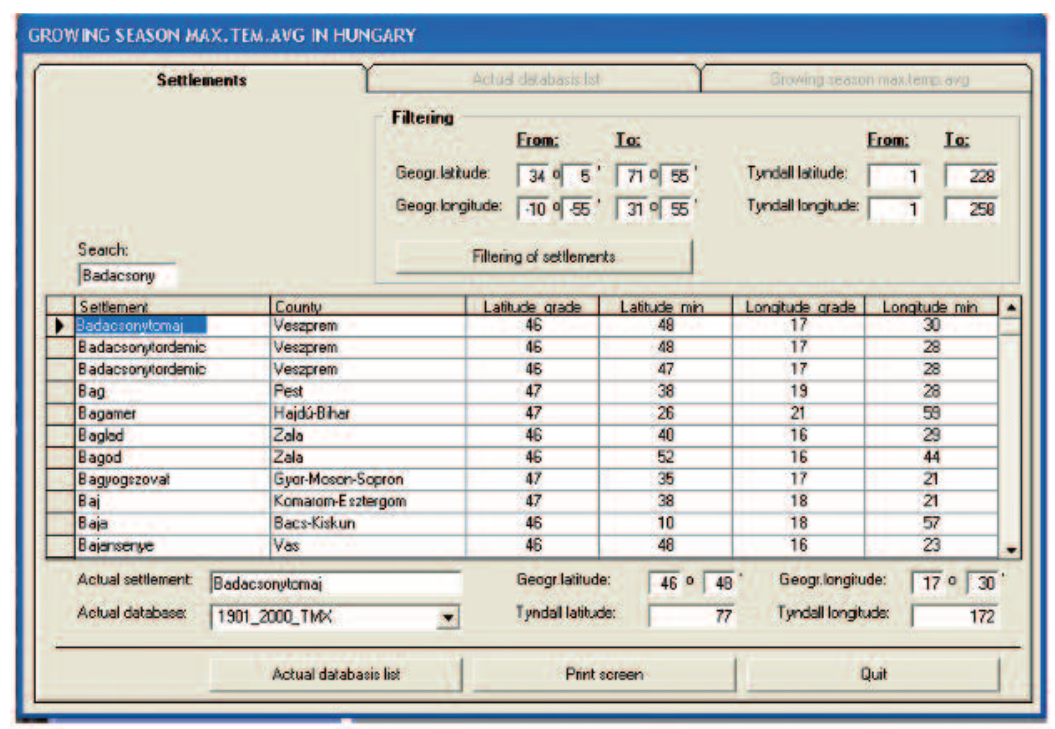

Figure 5: Selection of maximum temperature data for time series 1901-2000

interval of the past 100 years, it has remained practically unchanged in Debrecen. At the same time it is also obvious that heat waves are much more frequent and as a general rule, also last significantly longer in Budapest. The figure also shows that Budapest produced what by today's standard an „extremely" long is, a 12-day heat wave that, nevertheless, fades in proportion compared to the events of the entire period. In our enquiry we often came across with such remarkably outstanding yet infrequently occurring events which, notwithstanding, require attention because of their extreme values that are usually in the background of meteorological catastrophes.

Now let us examine the distribution of heat waves in the case of the scenarios of the three different model runs described earlier. Figure 7 shows the distribution of the length of the heat waves - defined by the NPHMOS - with different lengths but of at least 3 days, in the case.
The difference is remarkable. Heat waves are expected not only to be more frequent but they will also be extremely protracted in length. Against the historical data, a 12-day heat wave can be regarded as of extreme length, heat waves with length of $1-2$, or even 3 months are relatively frequent in the $\mathrm{HC}$ runs. As a matter of fact, this means that in some of the modelled future years the whole summer is an only long heat wave. Although results of the MP appear to be essentially more steady, we should note that frequency values as well as the lengths of heat waves may double or in some cases even treble in the future. We come to similar result by examining the case of Debrecen (Figure 8) The frequency values are very close to each another, however, the proportion of the occurrence of heat waves shows considerable growth. The same can be recognized in the length of heat waves. In both cases a tenfold growth may be reached and in some cases exceeded. A comparison of the diagrams of the cities reveals significant similarity in both the outstanding values and the values of great frequency. This is presumably explained by the fact that the expected heat waves, rather than appearing as heat islands, will have a geographically large expansion. In other words, from the point of view of the extreme values the year under scrutiny is more important than the place of examination. To support this allegation let us look at two comparative figures for the model runs producing the highest and lowest frequencies (Figures 9 and 10).

It can be seen in both figures that while the characters of the curves are identical, their values are also more or less the same regardless of which model run we consider. This, in essence, supports our presumption that heat waves depend much more on global meteorological conditions than on geographical distances. To prove this allegation it might be worth to examine several other towns, but in the absence of data, we need to delay this study.

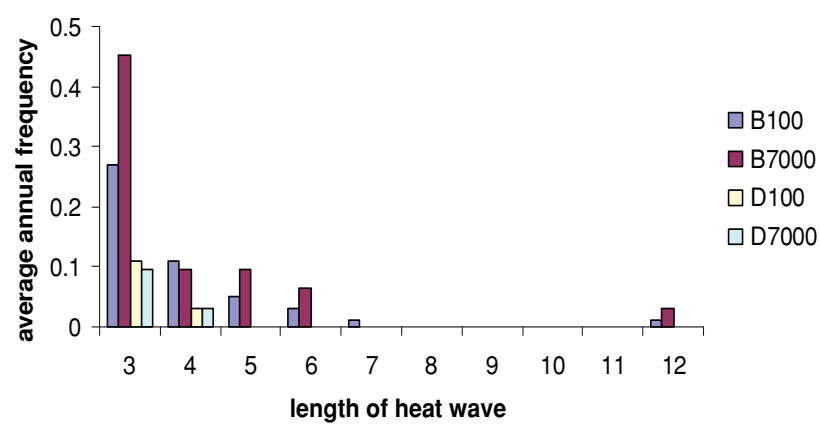

Figure 6: Distribution of heat waves in Budapest and Debrecen between 1901-2000, (B100, D100) and 1970-2000 (B7000, D7000) 


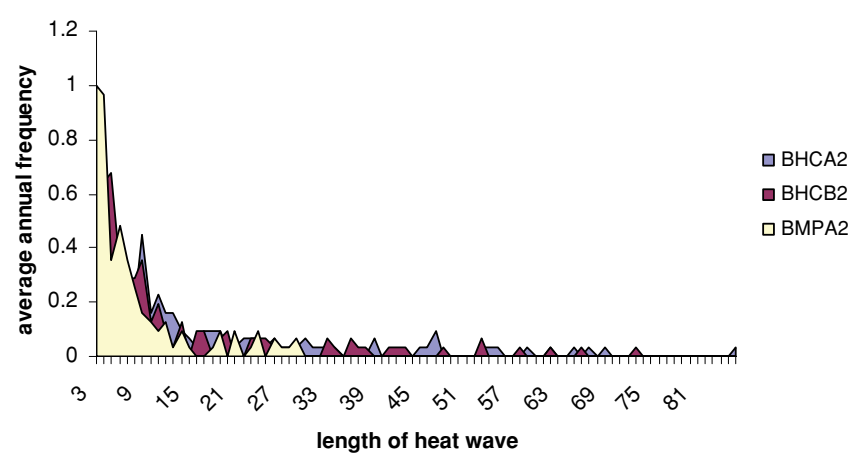

Figure 7: Distribution of heat waves in Budapest in 2070-2100 based on the NPHMOS definition (B-Budapest, HC-Hadley Center, MP-Max Planck Institute)

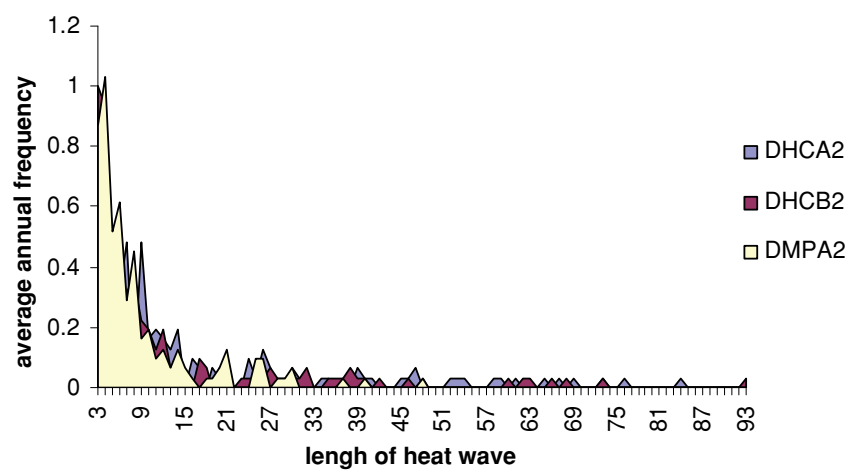

Figure 8: Distribution of heat waves by the NPHMOS definition in Debrecen in 2070-2100 (B-Budapest, HC-Hadley Center, MP-Max Planck Institute)

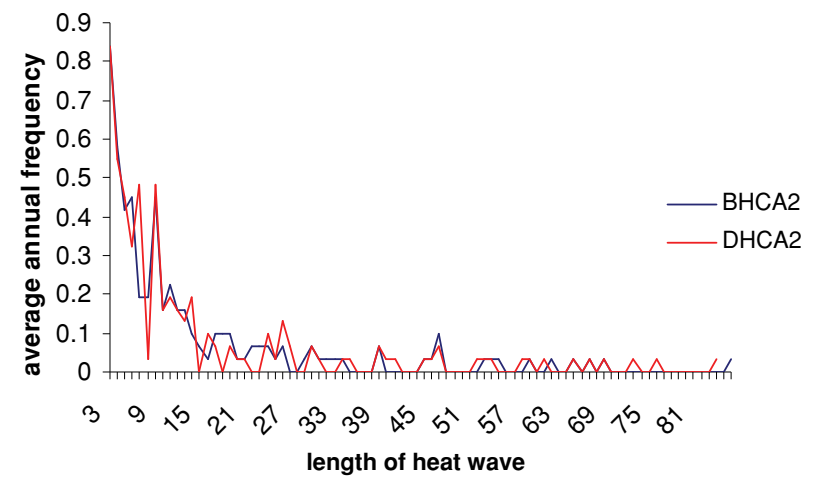

Figure 9: Distribution of heat waves in Budapest and Debrecen between 2070-2100 with the A2 model run of the Hadley Centeron the basis of the NPHMOS definition

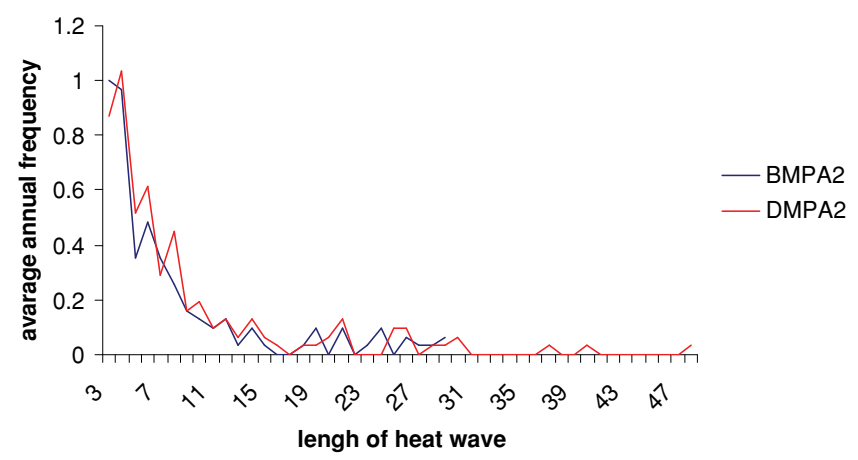

Figure 10: Distribution of heat waves in Budapest and Debrecen between 2070-2100 with the A2 model run by the Max Planck Institute based on the NPHMOS definition

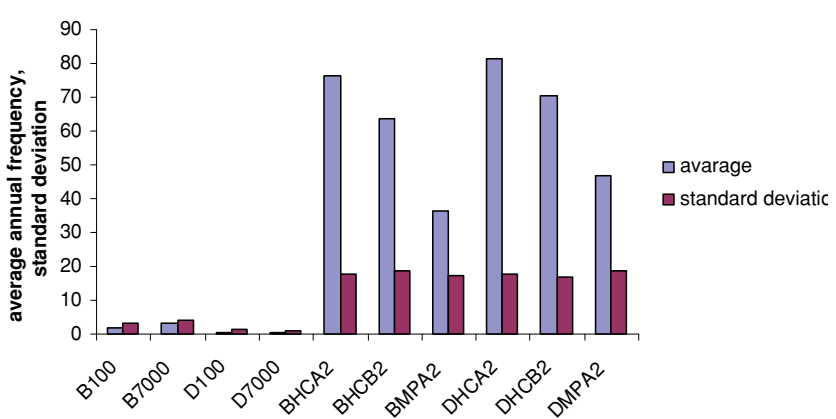

Figure 11: Average number of heat wave days and their standard deviation in the historical set of data and model runs based on the NPHMOS definition

Another question of interest is the average annual number of heat wave stricken days in the historical data and in the model runs. This is an important figure, because quite obviously, long but rarely occurring events must have a greater weight than shorter heat waves when considering risk factors. It can be seen that there is a dramatic rise in the number of heat wave stricken days regardless of what basis we select or which town we examine (Figure 11). It can also be seen that the model runs influence the occurrence of events more than the scenarios themselves do, as in the case of both cities, the difference between scenarios $\mathrm{A} 2$ and $\mathrm{B} 2$ is smaller than the difference between the same scenarios of the two institutions. It is quite peculiar that in the case of the model runs, the value of standard deviation is around 20 days, although the mean value is between 40 and 80 . The average values of Debrecen are just a little over those of Budapest which is all the more remarkable, as the values shown by the historical data are by and large „negligible” when compared to future values, yet, it can be seen that the situation used to be just the opposite in the past. Regarding the historical values, the uncertainty is reflected in the fact that the standard deviation exceeds the average value in every case, which makes clear that heat wave days in the past are connected to the ,warmer years". In other words, in some years there were several heat waves, while in others there were none. The values generated by the model runs show nothing like that. Relative deviation is much smaller than in the case of the historical set of data, which clearly amounts to state that it is not possible to predict the exact number and length of heat waves in the various scenarios, while the number of heat wave days can be forecasted with ,relatively great" accuracy.

\section{Examining the Intensity of Heat waves}

As mentioned earlier in my description of the relevant definitions, although heat wave is a term we can easily define from a agricultural point of view and we can also safely say when a heat wave alarm should be called, the definitions contain no information whatsoever on the intensity of heat waves. But as the intensity of a heat wave might determine its varying effect on different plants, it is worth to examine the intensity as well as the length of each heat wave. Therefore we plotted the distribution of the outlier temperature values of the 


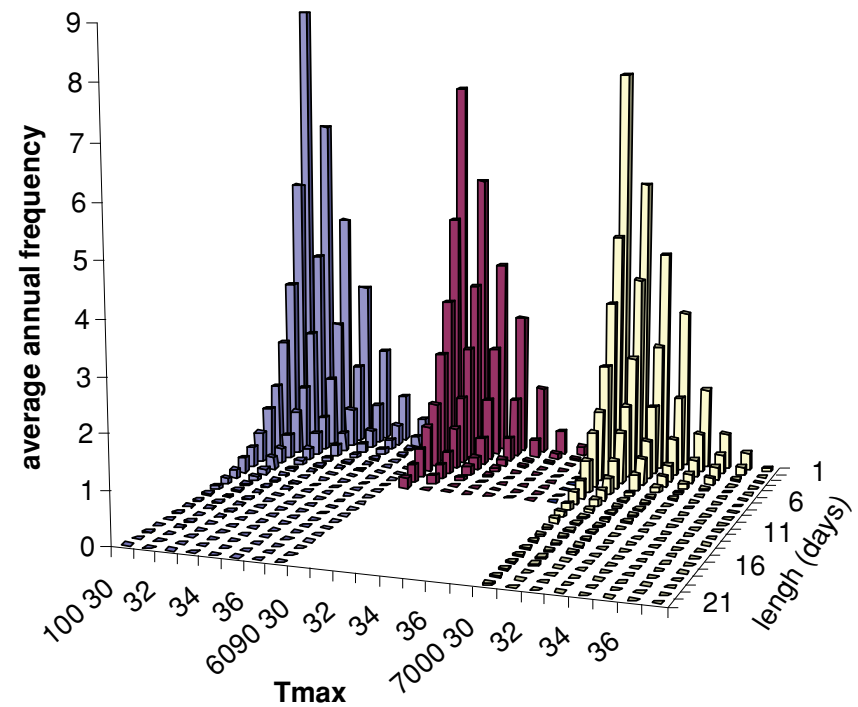

Figure 12: Distribution of the length and intensity of the maximum temperature "heat waves" for the three base periods, cumulated by temperature levels

most typical three base periods used in climate research (1901-2000, 1960-1990, 1970-2000). In our first study we examined maximum temperatures instead of the usual average temperatures, as extremely high values stand out more clearly in this sample. Figure 12 shows the distribution of the above mentioned three time intervals cumulated by temperature levels, revealing, in other words, in the period the average annual number of ,heat waves" lasting for t days and characterized by a temperature of at least $\mathrm{T}$. In this classification we did not yet narrow down the definition of a heat wave to events that would last for at least three days.

Based on the chart it is difficult to draw a line of distinction between the three distributions. It can be seen that the highest values, surprisingly, are contained in the 100 year set of data; but its decreasing phase is steeper than in the case

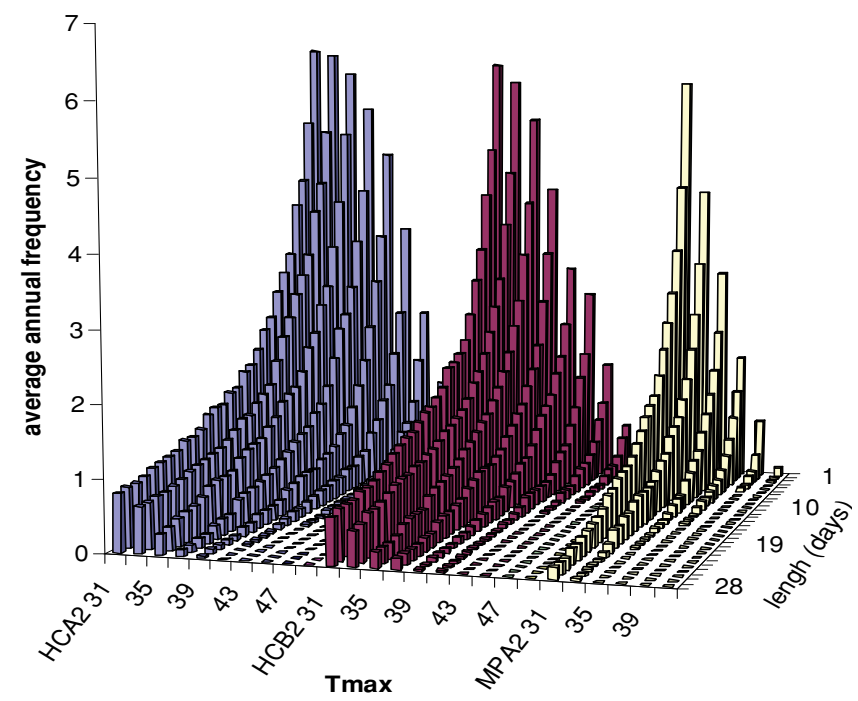

Figure 13: Distribution of the length and intensity of the maximum temperature "heat waves" of the three model runs in Budapest (2070-2100), cumulated by temperature levels of the other two diagrams (this means that outstandingly warm periods occurred not only at the end of the 20th century but also before that, but the heat waves experienced by the end of the century were either warmer or longer than the earlier ones), although the difference is insignificant. As seen on the scales of the figures, the classification involves maximum temperature levels over $30{ }^{\circ} \mathrm{C}$, because this is roughly the level where the daily average also exceeds the threshold of heat wave alarm.

We carried out the same enquiry also for the three model runs (Figure 13). The difference is too striking to need any further explanation. All one might say is that the values have grown to such an extent that for technical reasons we could not represent frequencies in one and the same scale, as the $30^{\circ} \mathrm{C}$ value was accompanied by an extremely protracted length of time (even as it is, we can only show the values in a reduced scale), while on the other hand, we found we had such high temperature levels that in the interest of representation we had to desist from using a $1{ }^{\circ} \mathrm{C}$ scale unit.

Yet, to be able to make some comparison, we produced a „best case" comparison, comparing the distribution of the highest frequency values (100 year) with the run of the model (MPA2) with the lowest values of frequency (Figure 14). All its interpretation may require is to say that had we represented three-day events that are now regarded as standard, the heat waves of the historical data could practically not be seen in the Figure, being so small in size by comparison to the data of the scenario.

Finally, here is a comparison of the numerical data of some past and expected "future" events:

- The longest $31{ }^{\circ} \mathrm{C}$ maximum temperature heat wave we have had lasted for 18 days in the past and lasts for 87 days in the runs.

- In the case of heat waves lasting for at least three days the highest maximum temperature recorded was $37^{\circ} \mathrm{C}$ in the past while the runs envisage ones of $49^{\circ} \mathrm{C}$.

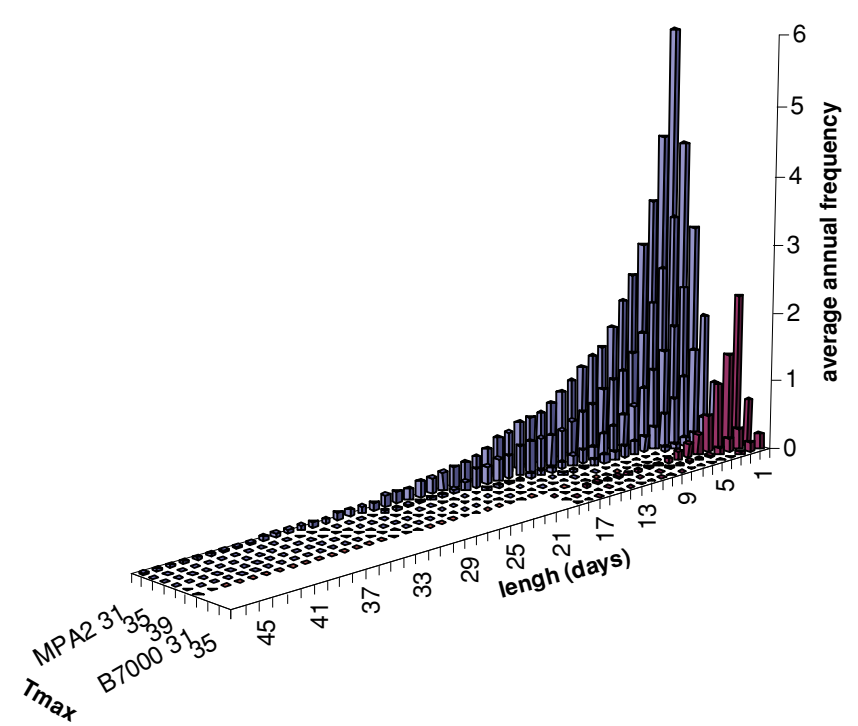

Figure 14: Comparison of the heat waves of MPA2 and the set of historical data from 1901-2000. 
- Past records show heat waves with a maximum temperature reaching or exceeding $31{ }^{\circ} \mathrm{C}$ and lasting for at least 3 days lasting on average for 10.1 days, as opposed to some of the runs with an average reaching 92.5 days.

These are quite staggering figures. Considering these three data alone, they might mean that in case the scenarios come true, practically the whole summer will be one long heat wave, with its peaks higher by $12{ }^{\circ} \mathrm{C}$ when we come to the period between 2070 and 2100. This appears unbelievable at first glance, for these scenarios envisage an average temperature rise of "only" $5-6^{\circ} \mathrm{C}$ at worst.

\section{References}

Harnos, Zs. (2007): Klímaváltozással összefüggő hazai kutatások: a VAHAVA folytatása. „KLÍMA-21” Füzetek, 49: 3-15.

Szenteleki K., Ladányi M., Erdélyi É., Horváth L., Hufnagel L. \& Révész A. (2007): A KKT klímakutatás adatbáziskezelő szoftver bemutatása Georgikon Konferencia, Keszthely 5 pp.

Szenteleki K. (2007): A Környezet - Kockázat - Társadalom (KLIMAKKT) klímakutatás adatbázis-kezelő rendszerei. „KLIMA-21” Füzetek, 51: 89-115.
Szenteleki, K., Ladányi, M., Szabó, É., Horváth, L., Hufnagel L., Solymosi, N. \& Révész, A. (2007): Introducing the KKT climate research database management software EFITA Conference, Glasgow. Intergovernmental Panel on Climate Change. Fourth Assessment Report "Climate Change 2007"

Prediction of Regional scenarios and Uncertainties for Defining EuropeaN Climate change risks and Effects, http://prudence.dmi.dk.

Horváth, L. \& Gaál, M. (2006): Spatial analogies in service of climate change analysis 6th Annual Meeting of the EMS / 6th ECAC 4 - 8 September 2006 Ljubljana, Slovenia abstract cd-rom.

Solymosi, N., Maróti-Agóts, A., Ózsvári, L., Könyves, L., Horváth, L. \& Kern, A. (2007): Region specific heat stress forecastfor cattleproduction based on climatechange. GISVET'07, Coppenhagen, 22-24 August 2007. (9) L. Horváth, M. Gaál, N. Solymosi (2007) Spatial analogues in climate change research EFITA/WCCA 2 - 5 July 2007, Glasgow, Scotland, Paper CD ROM p 22.

Schär, C., Vidale, P. L., Lüithi, D., Frei, C., Häberli C., Liniger M. A. \& Appenzeller, C. (2004.): The role of increasing temperature variability in European summer heat waves. Nature, 427, 332-336.

Beniston, M. \& Diaz, H. F.(2004): The 2003 heat wave as an example of summers in a greenhouse climate? Observations and climate model simulations for Basel, Switzerland. Global and Planetary Change 44. (1-4): 73-81

Poumadère, M., Mays C., Le Mer, S. \& Blong, R. (2005): The 2003 Heat Wave in France: Dangerous Climate Change Here and Now. Risk Analysis, 25 6: 1483-1494. 